\title{
A critical exploration of blood and environmental chromium concentration among oral cancer patients in an oral cancer prevalent area of Taiwan
}

\author{
Chi-Ting Chiang • Tsun-Kuo Chang • \\ Yaw-Huei Hwang $\cdot$ Che-Chun Su • \\ Kuo-Yang Tsai · Tzu-Hsuen Yuan · Ie-Bin Lian
}

Received: 21 May 2010/Accepted: 7 October 2010

(C) Springer Science+Business Media B.V. 2010

\begin{abstract}
The growing incidence of oral cancer (OC) in Taiwan has become a crucial public health concern. In particular, Changhua, a county in central Taiwan, carries persistently high OC incidence rate, with an alarmingly high male/female ratio of OC incidence. Previous epidemiological studies had found that the incidence is spatially correlated with the level of soil content to certain heavy metals in the central Taiwan area. Soil and the human body both intake environmental heavy metals, which can be absorbed through various ways. The soil metal concentration is an index of possible environmental exposure to heavy metal,
\end{abstract}

\section{C.-T. Chiang · T.-K. Chang}

Department of Bioenvironmental Systems Engineering,

National Taiwan University, Taipei City, Taiwan

\section{Y.-H. Hwang · T.-H. Yuan}

Graduate Institute of Occupational Medicine

and Industrial Hygiene, National Taiwan University,

Taipei City, Taiwan

C.-C. $\mathrm{Su}$

Department of Internal Medicine, Changhua Christian

Hospital, Changhua City, Taiwan

K.-Y. Tsai

Department of Oral and Maxillofacial Surgery, Changhua

Christian Hospital, Changhua City, Taiwan

I.-B. Lian (ه)

Graduate Institute of Statistics and Information Science, National Changhua University of Education, No. 1, Jin-De Road, Changhua City, Changhua 50007, Taiwan

e-mail: maiblian@cc.ncue.edu.tw and the blood metal concentration somewhat reflects the level of the exposure on the human body. Metallic carcinogen is likely to generate free radicals and play a role in many cancers, and many studies had reported that environmental exposure to heavy metals is an important risk factor for developing cancer. Studies on animals showed that chronic intake of chromium $(\mathrm{Cr})$ could induce OC. This study aims to explore the association between the $\mathrm{Cr}$ concentration in the farm soil and in the blood of OC patients. We recruited 79 OC patients from Changhua County, with their lifestyle being adjusted in regression analysis. The results showed that the $\mathrm{Cr}$ concentration in the blood of OC patients is significantly higher than the background value, and is positively associated with the $\mathrm{Cr}$ concentration in the soil surrounding their residence ( $p$-value $<0.023$ ). Because Changhua County is only with moderate prevalence of the known OC habitual risk factors, an environmental factor related to heavy metal $\mathrm{Cr}$ exposure is suspected. Future investigations may verify the causal relation between $\mathrm{Cr}$ and $\mathrm{OC}$.

Keywords Chromium - Whole blood . Environment · Oral cancer - Soil pollution

\section{Introduction}

Soil absorbs heavy metals and other pollutants released by anthropogenic activities. Unlike organic pollutants, 
heavy metals do not decay with time due to their bio-accumulative and non-biodegradable properties. Therefore, soil pollution by heavy metals has recently raised concerns. In Taiwan, heavy metals such as arsenic (As), cadmium (Cd), chromium (Cr), copper $(\mathrm{Cu})$, mercury $(\mathrm{Hg})$, nickel $(\mathrm{Ni})$, lead $(\mathrm{Pb})$ and zinc $(\mathrm{Zn})$, are widely used in various industrial plants (Lin et al. 2004). Changhua County, located in central Taiwan, is known as the granary of Taiwan, where soil has been seriously polluted by heavy-metal-contaminated industrial wastewater through irrigation channels. Previous studies have revealed a significant relationship between the local spatial patterns of soil heavy metal pollution, industrial plants locations and irrigation systems in northern Changhua County (Lin and Chang 2000a, b; Lin et al. 2001, 2002a). In addition, the soil heavy metals $\mathrm{Cr}, \mathrm{Cd}$ and $\mathrm{Ni}$ are associated with the location and number of the electroplating and metal surface treatment industrial plants in Changhua County (Lin et al. 2002b). Two recent studies by National Health Research Institutes (NHRI) in Taiwan have found that the levels of blood $\mathrm{Cr}$ and urinary $\mathrm{Ni}$ of residents living in the metalfactory-dense areas of Changhua County were higher than people who lived in other areas (Chang et al. 2006a, b). The facts suggested that the discharged heavy metal which had polluted the farm soil, might have as well entered the human body via certain pathways.

Genetics, lifestyle, and environment influence health. Doctors have overlooked environmental effects. Geo-medicine is a new branch of environmental medicine, which studies adverse effects of the environment on the human body (Låg 1990). Many heavy metals, including $\mathrm{Cr}$, have been classified as human carcinogens (IARC 1990). Occupational exposure to $\mathrm{Cr}$ significantly decreases the age at the onset of lung cancer (Halasova et al. 2009) and also increases the risk of lung cancer, brain tumor and malignant lymphoma (Beveridge et al. 2010; Hara et al. 2010). For non-occupational exposure to $\mathrm{Cr}$, human oral exposure to hexavalent $\mathrm{Cr}[\mathrm{Cr}(\mathrm{VI})]$ in drinking water revealed a statistically significant increase in stomach cancer (Beaumont et al. 2008; Sedman et al. 2006). As a result, exposure to heavy metals in the air, water and soil may increase cancer risk. Some studies also indicate that the high content of soil heavy metals in the region had high mortality or morbidity rates of several types of cancers, e.g., stomach, prostate, bladder, esophageal and gastrointestinal cancers (Albanese et al. 2008; Rheeder et al. 1994; Stocks and Davies 1964; Türkdoğan et al. 2002).

In Taiwan, oral cancer (OC) ranked as the fourth most frequent male cancer. Betel quid chewing (BQC) and cigarette smoking (CS) are known to be the most important risk factors of OC in Taiwan (Ko et al. 1995). Changhua has the highest OC incidence among 23 counties and the abnormally high male/female ratio of OC incidence (Chiang et al. 2010); however, its BQC and CS are only moderately prevalent. Therefore, we suspect other unknown environmental risk factors in the area $\mathrm{Su}$ et al. 2007).

So far, there are insufficient epidemiologic and animal studies that link ingestion of heavy metals with human OC. Metal dust containing $\mathrm{Cr}$ and $\mathrm{Ni}$ increases the risk of $\mathrm{OC}$ in machine worker (Tisch et al. 1996). Occupational exposure to $\mathrm{Cr}(\mathrm{VI})$ compounds might increase the risk for oral squamous cell cancer (Tisch and Maier 1996). However the animal studies conducted by the U.S. National Toxicology Program (NTP) of the National Institutes of Health (NIH) had found that chronic exposure to $\mathrm{Cr}(\mathrm{VI})$ induced OC in rats (Stout et al. 2009). A recent epidemiological study shows that the incidence rates of OC of townships in Taiwan have strong spatial correlations with the concentration of certain heavy metals of the local farm soil, including $\mathrm{Ni}$ (Su et al. 2010). The concentrations of $\mathrm{Ni}$ and $\mathrm{Cr}$ in soil are highly correlated in Changhua County of Taiwan (Lin 2002; Lin et al. 2002b), thus the OC incidence is also spatially associated with $\mathrm{Cr}$. Among the entire county in Taiwan, Changhua has the highest $\mathrm{Ni}$ and $\mathrm{Cr}$ concentrations in the farm soil (ROCEPA 1985). Changhua County is the main hub of electroplating industry in Taiwan, where more than $60 \%$ of the electroplating factories (EF) are located. In particular, its $\mathrm{Cr}$ pollution is synthetic, since large amounts of industrial wastewater containing $\mathrm{Cr}$ are usually released into soil or groundwater without proper treatment (Chang et al. 1997). The distribution of $\mathrm{Cr}$ concentration in soil spatially correlates with the location of EF (Lin et al. 2002b).

The next question is whether the high $\mathrm{Cr}$ concentration in soil affects the human body. A clinical study in Changhua County showed that OC patients living in the area of high-density EF had poorer prognoses than those living in the area of low-density 


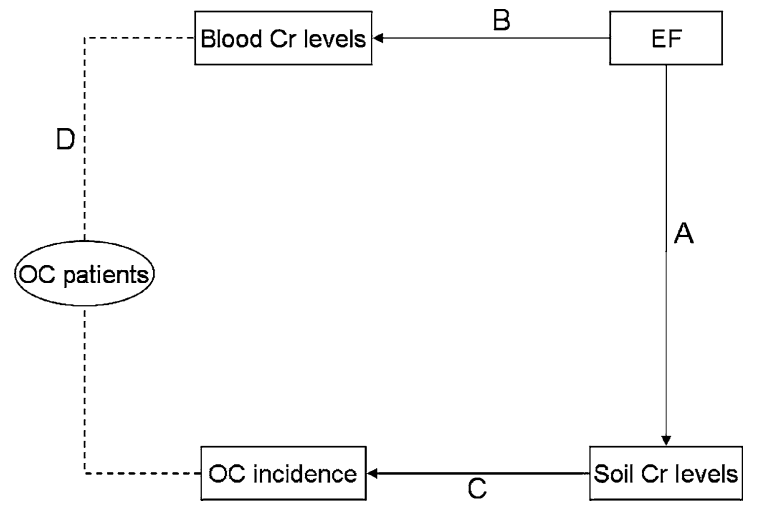

Fig. 1 An overall framework of the relationships among electroplating factory $(E F)$, chromium $(C r)$ and oral cancer $(O C)$. The purpose of this study was to establish the association between the $\mathrm{Cr}$ levels in the blood of OC patients and in the farm soil around their residence. Linkage $A$ indicates that $\mathrm{Cr}$ level in the soil is associated with the location and number of EF. Linkage $B$ indicates that $\mathrm{Cr}$ levels in the blood of residents living in the high-density areas are higher than those in the low-density areas in Changhua County. Linkage $C$ indicates that the OC incidence rates of Taiwan's townships have spatial correlations with the levels of certain heavy metals of the local farm soil. Linkage $D$ signifies the $\mathrm{OC}$ patients have higher $\mathrm{Cr}$ level in the blood than the healthy residents in Changhua County

$\mathrm{EF}$ (Su et al. 2008). Figure 1 shows the relation between OC and these heavy metals.

$\mathrm{Cr}$ concentrations in red blood cells and plasma of human can have sustained elevation following ingestion of Cr-containing water (Kerger et al. 1997). In this study, we explore the association between OC and heavy metal $\mathrm{Cr}$ by focusing on the OC patients who live in Changhua County, and investigating the association between the $\mathrm{Cr}$ concentration in their blood and soil. The main purpose of this study was to establish a link between $C$ and D in the relationship framework of the overall study (Fig. 1).

\section{Materials and methods}

Study area and subjects

Study subjects were recruited from the Changhua Christian Hospital $(\mathrm{CCH})$, the exclusive medical center in Changhua, during 2008-2009. After excluding participants who did not complete the questionnaire, 79 pathologically proved OC patients from the Oral and Maxillofacial Surgery Division were enrolled. Figure 2 shows the distribution of $\mathrm{OC}$ patients in the study area. All participants lived in Changhua County. The average age was $56.2 \pm$ 9.1 years old, ranging from 38 to 76 years old. The Institutional Review Board (IRB) approved this study at $\mathrm{CCH}$ (protocol no. CCH 070910) in May 2008.

Questionnaire design and administration

After clinic visits, the OC patients who signed consent forms were interviewed to collect detailed information on demographics, lifestyle, smoking, alcohol, betel quid consumption, environmental and occupational exposure history, and family history of cancer. To describe the surrounding environment of the residence, we designed some questions to characterize the environmentally polluted situation, each with dichotomous categories. A residence located nearby environment potentially polluted indicated a foul smell or a factory located less than one kilometer from his/her own residence, or a household factory.

Analysis of blood samples

Three milliliter venous blood samples from each subject were drawn into BD Vacutainer ${ }^{\circledR}$ tubes with ethylenediaminetetraacetic acid (EDTA) anticoagulant and stored at $4{ }^{\circ} \mathrm{C}$. During pretreatment, blood samples were first diluted by ten-fold with diluents containing $0.01 \mathrm{~mol} \mathrm{~L}^{-1}$ of ammonium hydroxide solution, $10 \mathrm{~mol} \mathrm{~L}^{-1}$ Triton $\mathrm{X}-100$ and 0.0002 mol L ${ }^{-1}$ EDTA (Case et al. 2001). All diluted blood samples were filtered with a $0.45-\mu \mathrm{m}$ filter, and analyzed for the levels of $\mathrm{Cr}$ by inductively coupled plasma mass spectrometry (ICP-MS, Agilent 7500c) (Barany et al. 1997). For precision, spikes were examined per ten samples to ensure measurement stability during the analysis. The maximum acceptable value for relative percent difference was set to $10 \%$. For the accuracy assessment, certified reference material (CRM), whole blood Seronorm L1 \& L3, which contain low and high concentrations of $\mathrm{Cr}$ were analyzed. The accuracy assessment showed that the relative error for measuring $\mathrm{Cr}$ in CRM was lower than $10 \%$. In the following statistical analysis and presentation, one-half of the method detection limits (MDL/2) for the specific metal was allocated to these samples if the metal levels in blood were below the MDL. The MDL for the blood $\mathrm{Cr}$ measurement was 
Fig. 2 Study area and the geographic locations of subjects

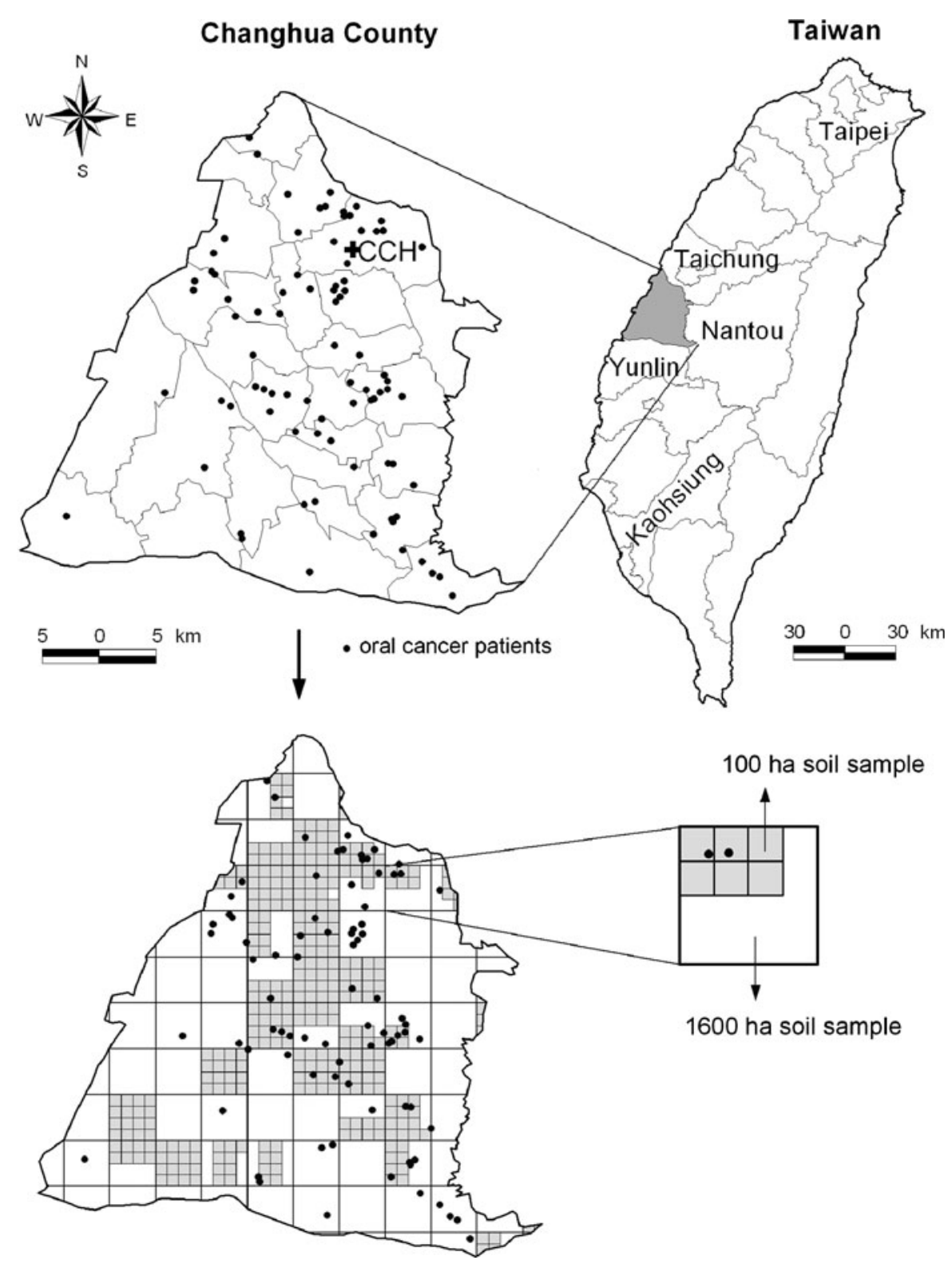

$0.14 \mu \mathrm{g} \mathrm{L}^{-1}$. All blood samples were collected in the late morning or afternoon; therefore, the accuracy of the $\mathrm{Cr}$ determination is not likely to be affected by the collection time.

Data on the contents of soil heavy metals

Data in this study were derived from a progressive, nationwide survey that determined the concentration in topsoil $(0-15 \mathrm{~cm})$ of certain heavy metals, obtained from the Environmental Protection Administration
(EPA) in Taiwan from 1983 to 1990 (ROCEPA 1985). The first phase of the soil survey during 1983-1986 used a grid cell size of 1,600 ha as a sampling unit. The 100 ha sampling unit size was used in the second phase during 1987-1990. The EPA (Taiwan) classified the concentrations of soil heavy metals into five classes based on these measurements collected in the first phase of soil survey. The first, second, and third classes represent no soil heavy metal pollution. However, the fourth and fifth classes are required to carry out further intensive sampling and monitoring in the second phase 
of the soil survey. The concentration of extractable $\mathrm{Cr}$ in the soil was determined by the $0.1 \mathrm{~N} \mathrm{HCl}$ extraction method. These soil samples were geographically distributed sites in Changhua County, displayed in Fig. 2.

The exact coordinate locations (longitudes and latitudes) for each OC patient's residence were determined through a visual aerial survey using Google Earth $^{\circledR}$. A geographic information system (GIS) mapped the coordinates of OC patients and linked the location to individual (i.e. gender, age, $\mathrm{BQC}, \mathrm{CS}$ and blood $\mathrm{Cr}$ level) and environmental (i.e. the concentrations of heavy metal $\mathrm{Cr}$ in the farm soil) information. The representative soil concentration of $\mathrm{Cr}$ for each OC patient depended on his/her residence within the soil sampling grid of the $\mathrm{Cr}$ concentration.

Statistical analysis

The Welch's 2-sample $t$ test was used to compare the $\mathrm{Cr}$ measurements in OC patient's blood with the background values, obtained from 641 non-cancer residents in Changhua County from the study by Chang et al. (2006b), with respect to the overall stratified means of three age groups.

Piecewise linear regression and nonparametric rank regression were applied to fit the log-transformed $\mathrm{Cr}$ concentrations in the blood $(\log \mathrm{B}-\mathrm{Cr})$ of OC patients on the log-transformed $\mathrm{Cr}$ concentrations in the corresponding farm soil (log S-Cr). To cope with multiple confounders, the regressions were adjusted by the extended balancing score $b(Z)$ (Lian 2003) to eliminate the confounding effect by covariates Z's, e.g., demographic variables (age, gender, etc.) and lifestyle factors (CS, BQC). The effect was considered significant with $p$-value $<0.05$.

\section{Results}

Description of the characteristics of OC patients

Table 1 shows the basic demographics of the OC patients from Changhua County. Among them, 96\% are men, $40 \%$ aged between 50 and 59 years. The goodness-of-fit test (not shown) indicates that the age distribution is similar to the nationwide 5273 OC cases in 2002 (released by Taiwan Cancer registration). Welch's 2-sample $t$ test indicates that the $\mathrm{Cr}$ in
Table 1 Chromium in whole blood of oral cancer patients in the study, compared with that in non-cancer residents, from Changhua County, Taiwan

\begin{tabular}{|c|c|c|c|c|}
\hline \multirow[t]{2}{*}{ Variables } & \multicolumn{2}{|c|}{ OC patients } & \multicolumn{2}{|c|}{ Non-cancer residents } \\
\hline & $N$ & Mean (SD) & $N$ & Mean (SD) \\
\hline $\mathrm{B}-\mathrm{Cr}\left(\mu \mathrm{g} \mathrm{L}^{-1}\right)$ & 79 & $0.795 * *(0.260)$ & 641 & $0.441(0.392)$ \\
\hline \multicolumn{5}{|l|}{ Age (years) } \\
\hline $35-44$ & 10 & $0.669 *(0.181)$ & 205 & $0.498(0.522)$ \\
\hline $45-54$ & 23 & $0.779 * *(0.242)$ & 213 & $0.425(0.312)$ \\
\hline $55-64$ & 29 & $0.865 * *(0.263)$ & 223 & $0.403(0.308)$ \\
\hline$\geqq 65$ & 17 & $0.771(0.299)$ & & \\
\hline \multicolumn{5}{|l|}{ Gender } \\
\hline Male & 76 & $0.789(0.259)$ & & \\
\hline Female & 3 & $0.951(0.286)$ & & \\
\hline \multicolumn{5}{|l|}{ Smoking } \\
\hline Non-smoker & 7 & $0.950(0.248)$ & & \\
\hline Smoker & 72 & $0.780(0.258)$ & & \\
\hline \multicolumn{5}{|l|}{ Drinking } \\
\hline Non-drinker & 24 & $0.829(0.225)$ & & \\
\hline Drinker & 55 & $0.780(0.274)$ & & \\
\hline \multicolumn{5}{|l|}{ Chewing } \\
\hline Non-chewer & 8 & $0.809(0.262)$ & & \\
\hline Chewer & 71 & $0.793(0.261)$ & & \\
\hline
\end{tabular}

$N$ number of subjects, $S D$ standard deviation

The measurements $\left(\mu \mathrm{g} \mathrm{L}^{-1}\right)$ of OC patients were compared with non-cancer residents in Changhua from the study by Chang et al. (2006b) by Welch's $t$ test. Those with $p$-value $<0.05$ and $<0.01$ are noted by $*$ and $* *$, respectively

the blood of OC patients is significantly higher than the background values obtained from 641 non-cancer residents in Changhua, with respect to both the overall and the stratified means of three age groups. The overall arithmetic mean of whole blood $\mathrm{Cr}$ concentration was $0.795(\mathrm{SD}=0.26)$ and the geometric mean was 0.75 (GSD $=1.43$ ), nearly twofolds higher than the background values.

Most of the OC patients were habitual betel and cigarette consumers. There was no apparent difference in blood $\mathrm{Cr}$ concentration between consumers and non-consumers of these two risk factors. Although the female patients had higher average blood $\mathrm{Cr}$ concentration than men, the difference was not significant due to the small sample size (three women to 76 men) in the study. The gender ratio was consistent with that in the Taiwan population, such that OC is male-dominant with male patients constituting $88 \%$ (Su et al. 2007). The wide gap is possibly 
due to the prevalence of the major risk factor, betel quid chewing, which is 11-fold higher for men than women (Tsai et al. 2009).

Relationship between the chromium levels in blood and farm soil

Figure 3 shows the positive correlation between $\log \mathrm{B}-\mathrm{Cr}$ and $\log \mathrm{S}-\mathrm{Cr}$ of OC patients. Both piecewise linear regression and nonparametric rank regression suggest that $\mathrm{S}-\mathrm{Cr}$ is significantly associated with $\mathrm{B}-\mathrm{Cr}$ in OC patients, with $p$-values at 0.010 and 0.0222 , respectively. The insignificant balancing score indicates that confounding effects by other covariates are negligible. The coefficients of Pearson's correlation and Spearman's rank correlation between the $\mathrm{Cr}$ concentrations in blood and soil were 0.32 and 0.30 , respectively, which were both statistically significant (data not shown).

\section{Discussion}

In Taiwan, potential anthropogenic sources that release $\mathrm{Cr}$ into the air, water, and soil include electroplating operation, textile manufacturing, leather tanning and pigments industries. Chromium has several oxidative states in toxicological potency. In environmental settings, Cr exists primarily in two valence states: hexavalent $[\mathrm{Cr}(\mathrm{VI})]$ and trivalent $[\mathrm{Cr}(\mathrm{III})]$ chromium. Chromium(VI) is a procarcinogen that causes DNAprotein crosslink in human lymphocytes (Taioli et al. 1995), and is classified as a known human carcinogen,

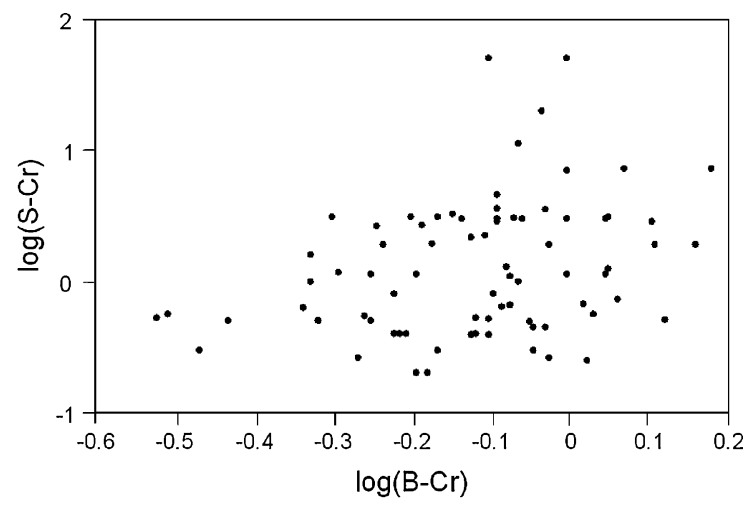

Fig. 3 The scatter plot of the correlation between $\mathrm{Cr}$ concentrations in blood $(\mathrm{B}-\mathrm{Cr})$ versus in the farm soil $(\mathrm{S}-\mathrm{Cr})$ associated with respiratory cancers (Langard 1990; Sorahan et al. 1998). In addition, oral exposure to $\mathrm{Cr}(\mathrm{VI})$-contaminated drinking water can increase the risk of stomach cancer in both human and animals (Beaumont et al. 2008; Sedman et al. 2006). The association with OC has only been proven in animal studies via oral exposure (Stout et al. 2009). Chromium(VI) is more soluble and more mobile than Cr(III) (Yassi and Nieboer 1988); elevated concentrations of $\mathrm{Cr}(\mathrm{VI})$ in soil are most likely caused by pollution (EC/HC 1994). The total $\mathrm{Cr}$ content in the farm soil of contaminated areas has profoundly negative impacts on nearby residents.

Several studies have addressed the association between heavy metals in the environment and heavy metals inside the human body. The high concentrations of specific metals in the environment may be responsible for the high concentrations of these metals in the blood, urine and hair. The Cr concentrations in urine and hair of the inhabitants living in the surrounding area of the chromite-ore processing plant correlated with the environmental exposure (Rosas et al. 1989). Lin et al. (2002b) found that $\mathrm{Cr}$ concentration in the soil is significantly associated with the location and number of the electroplating and metal surface treatment industrial plants in Changhua County (linkage A in Fig. 1). The chromium and nickel in polluted soil come from EF. Chang et al. (2006b) found that the Cr concentrations in the blood of the residents living in the high EF-density areas of Changhua are significantly higher than those in the low EF-density areas (linkage B in Fig. 1). A recent study by $\mathrm{Su}$ et al. (2008) further indicated that OC patients living in the high EF-dense areas of Changhua County have poorer long-term survival rates.

How do heavy metals get into the human body from the environment? They enter through soil $\rightarrow$ edible plants $\rightarrow$ human, i.e. the food chain pathway. For example, the mean concentrations of $\mathrm{Cr}, \mathrm{Ni}, \mathrm{Pb}, \mathrm{Zn}$ and cadmium $(\mathrm{Cd})$ in vegetables grown in wastewater-irrigated areas observed were beyond the safe limits of India (Gupta et al. 2008). The local residents in a metal-contaminated area have higher risk of consuming the contaminated agricultural products daily and are exposed to high levels of metals such as $\mathrm{Cr}(\mathrm{VI})$ and $\mathrm{Ni}(\mathrm{II})$, human carcinogens and mutagens.

A significantly positive association was found between the $\mathrm{Cr}$ concentration in the blood of $\mathrm{OC}$ 
patients and the $\mathrm{Cr}$ concentration in the farm soil around the residence of OC patients (linkage $\mathrm{C}$ and D, Fig. 1). The average concentration of whole blood $\mathrm{Cr}$ in OC patients $\left(0.80 \pm 0.26 \mu \mathrm{g} \mathrm{L}^{-1}\right)$ was much higher than the normal local residents $(0.44 \pm$ $0.39 \mu \mathrm{g} \mathrm{L}^{-1}$ ) in Changhua County. Most of the OC patients investigated were not factory workers; therefore we rule out occupational exposure. The findings coincide with the results of Younas et al. (1998), who suggested that average blood concentrations of heavy metals were significantly higher in cancer patients residing in and around the areas of heavy metal contaminated soil than healthy subjects.

A limitation of this study is the use of soil $\mathrm{Cr}$ concentration data derived from progressive soil since the 1980s, and the sampling unit in the soil survey corresponding to each patient does not necessarily represent the true environmental exposure. Nonetheless, soil can be regarded as both an emitter and a receiver of the environmental toxin; therefore, the $\mathrm{Cr}$ concentration in the farm soil can somewhat reflect the amount of $\mathrm{Cr}$ in the environment and reflect the risk that the residents in the vicinity are exposed to.

In conclusion, this study provides valuable findings for environmental effects on human health. Although the relatively small number of OC patients available for analysis has limited our study, the results still show a significantly positive correlation between the $\mathrm{Cr}$ concentrations in the blood and the nearby soil. Future studies should investigate the role of $\mathrm{Cr}$ in $\mathrm{OC}$ development.

Conflict of interest The authors declare that they have no competing interests.

\section{References}

Albanese, S., De Luca, M. L., De Vivo, B., Lima, A., \& Grezzi, G. (2008). Relationships between heavy metal distribution and cancer mortality rates in the Campania region, Italy. In B. De Vivo, H. E. Belkin, \& A. Lima (Eds.), Environmental geochemistry: Site characterization, data analysis and case histories (pp. 387-400). The Netherlands: Elsevier.

Barany, E., Bergdahl, I. A., Schutz, A., Skerfving, S., \& Oskarsson, A. (1997). Inductively coupled plasma mass spectrometry for direct multi-element analysis of diluted human blood and serum. Journal of Analytical Atomic Spectrometry, 12(9), 1005-1009.
Beaumont, J. J., Sedman, R. M., Reynolds, S. D., Sherman, C. D., Li, L. H., Howd, R. A., et al. (2008). Cancer mortality in a Chinese population exposed to hexavalent chromium in drinking water. Epidemiology, 19, 12-23.

Beveridge, R., Pintos, J., Parent, M. E., Asselin, J., \& Siemiatycki, J. (2010). Lung cancer risk associated with occupational exposure to nickel, chromium VI, and cadmium in two population-based case-control studies in Montreal. American Journal of Industrial Medicine, 53, 476-485.

Case, C. P., Ellis, L., Turner, J. C., \& Fairman, B. (2001). Development of a routine method for the determination of trace metals in whole blood by magnetic sector inductively coupled plasma mass spectrometry with particular relevance to patients with total hip and knee arthroplasty. Clinical Chemistry, 47(2), 275-280.

Chang, T. K., Hwang, K. J., \& Shyu, G. S. (1997). Using factor analysis to evaluate characteristic of metals in soil pollution. Journal of Taiwan Agricultural Engineering, 43(2), 11-19.

Chang, F. H., Wang, S. L., Huang, Y. L., Tsai, M. H., Yu, S. T., \& Chang, L. W. (2006a). Biomonitoring of chromium for residents of areas with a high density of electroplating factories. Journal of Exposure Science Environmental Epidemiology, 16(2), 138-146.

Chang, F. H., Wang, H. J., Wang, S. L., Wang, Y. C., Hsieh, D. P., Chang, L. W., et al. (2006b). Survey of urinary nickel in residents of areas with a high density of electroplating factories. Chemosphere, 65(10), 1723-1730.

Chiang, C. T., Hwang, Y. H., Su, C. C., Tsai, K. Y., Lian, I. B., Yuan, T. H., et al. (2010). Elucidating the underlying causes of oral cancer through spatial clustering in highrisk areas of Taiwan with a distinct gender ratio of incidence. Geospatial Health, 4(2), 230-242.

EC/HC (Environment Canada \& Health Canada). (1994). Canadian Environmental Protection Act: Priority substances list assessment report (PSL1): Chromium and its Compounds. EC/HC, Canada.

Gupta, N., Khan, D. K., \& Santra, S. C. (2008). An assessment of heavy metal contamination in vegetables grown in wastewater-irrigated areas of Titagarh, West Bengal, India. Bulletin of Environmental Contamination and Toxicology, 80(2), 115-118.

Halasova, E., Matakova, T., Kavcova, E., Musak, L., Letkova, L., Adamkov, M., et al. (2009). Human lung cancer and hexavalent chromium exposure. Neuroendocrinology Letters, 30(Suppl. 1), 182-185.

Hara, T., Hoshuyama, T., Takahashi, K., Delgermaa, V., \& Sorahan, T. (2010). Cancer risk among Japanese chromium platers, 1976-2003. Scandinavian Journal of Work, Environment and Health, 36, 216-221.

IARC (International Agency for Research on Cancer). (1990). Chromium, nickel and welding. IARC Monographs on the Evaluation of Carcinogenic Risks to Humans, 49, 1-36.

Kerger, B. D., Finley, B. L., Corbett, G. E., Dodge, D. G., \& Paustenbach, D. J. (1997). Ingestion of chromium(VI) in drinking water by human volunteers: Absorption, distribution, and excretion of single and repeated doses. Journal of Toxicology and Environmental Health, 50(1), 67-95. 
Ko, Y. C., Huang, Y. L., Lee, C. H., Chen, M. J., Lin, L. M., \& Tsai, C. C. (1995). Betel quid chewing, cigarette smoking and alcohol consumption related to oral cancer in Taiwan. Journal of Oral Pathology and Medicine, 24(10), 450-453.

Låg, J. (1990).General survey of geomedicine. In J. Låg (Ed.), Geomedicine (pp. 1-24). Boca Raton, FL: CRC press.

Langard, S. (1990). One hundred years of chromium and cancer: a review of epidemiological evidence and selected case reports. American Journal of Industrial Medicine, 17(2), 189-215.

Lian, I. B. (2003). Reducing over-dispersion by generalized degree of freedom and propensity score. Computational Statistics \& Data Analysis, 43(2), 197-214.

Lin, Y. P. (2002). Multivariate geostatistical methods to identify and map spatial variations of soil heavy metals. Environmental Geology, 42(1), 1-10.

Lin, Y. P., \& Chang, T. K. (2000a). Geostatistical simulation and estimation of the spatial variability of soil zinc. Journal of Environmental Science and Health Part AToxic/Hazardous Substances \& Environmental Engineering, 35(3), 327-347.

Lin, Y. P., \& Chang, T. K. (2000b). Simulated annealing and kriging method for identifying the spatial patterns and variability of soil heavy metal. Journal of Environmental Science and Health Part A-Toxic/Hazardous Substances \& Environmental Engineering, 35(7), 1089-1115.

Lin, Y. P., Chang, T. K., Shih, C. W., \& Tseng, C. H. (2002a). Factorial and indicator kriging methods using a geographic information system to delineate spatial variation and pollution sources of soil heavy metals. Environmental Geology, 42(8), 900-909.

Lin, Y. P., Chang, T. K., \& Teng, T. P. (2001). Characterization of soil lead by comparing sequential Gaussian simulation, simulated annealing simulation and kriging methods. Environmental Geology, 41(1-2), 189-199.

Lin, Y. P., Teng, T. P., \& Chang, T. K. (2002b). Multivariate analysis of soil heavy metal pollution and landscape pattern in Changhua county in Taiwan. Landscape and Urban Planning, 62(1), 19-35.

Lin, H. T., Wong, S. S., \& Li, G. C. (2004). Heavy metal content of rice and shellfish in Taiwan. Journal of Food \& Drug Analysis, 12(2), 167-174.

Rheeder, J. P., Marasas, W. F., Farina, M. P., Thompson, G. R., \& Nelson, P. E. (1994). Soil fertility factors in relation to oesophageal cancer risk areas in Transkei, Southern Africa. European Journal of Cancer Prevention, 3(1), 49-56.

ROCEPA. (1985). Survey of heavy metals in the soil samples. In Environmental Protection Administration of the Republic of China (Ed), Yearbook of environmental protection statistics Taiwan Area, the Republic of China, Taipei.

Rosas, I., Belmont, R., Baez, A., \& Villalobospietrini, R. (1989). Some aspects of the environmental exposure to chromium residues in Mexico. Water, Air, and Soil Pollution, 48(3-4), 463-475.

Sedman, R. M., Beaumont, J., McDonald, T. A., Reynolds, S., Krowech, G., \& Howd, R. (2006). Review of the evidence regarding the carcinogenicity of hexavalent chromium in drinking water. Journal of Environmental Science and Health Part C-Environmental Carcinogenesis \& Ecotoxicology Reviews, 24, 155-182.

Sorahan, T., Burges, D. C. L., Hamilton, L., \& Harrington, J. M. (1998). Lung cancer mortality in nickel/chromium platers, 1946-95. Occupational and Environmental Medicine, 55(4), 236-242.

Stocks, P., \& Davies, R. I. (1964). Zinc and copper content of soils associated with the incidence of cancer of the stomach and other organs. British Journal of Cancer, 18, 14-24.

Stout, M. D., Herbert, R. A., Kissling, G. E., Collins, B. J., Travlos, G. S., Witt, K. L., et al. (2009). Hexavalent chromium is carcinogenic to $\mathrm{F} 344 / \mathrm{N}$ rats and $\mathrm{B} 6 \mathrm{C} 3 \mathrm{~F} 1$ mice after chronic oral exposure. Environmental Health Perspectives, 117(5), 716-722.

Su, C. C., Chung, J. A., Hsu, Y. Y., Huang, S. J., \& Lian, I. B. (2008). Age at diagnosis and prognosis of oral cancer in relation to the patient's residential area: Experience from a medical center in Taiwan. Oral Oncology, 44(11), 1032-1038.

Su, C. C., Lin, Y. Y., Chang, T. K., Chiang, C. T., Chung, J. A., Hsu, Y. Y., et al. (2010). Incidence of oral cancer in relation to nickel and arsenic concentrations in farm soils of patients' residential areas in Taiwan. BMC Public Health, 10, 67.

Su, C. C., Yang, H. F., Huang, S. J., \& Lian I. B. (2007). Distinctive features of oral cancer in Changhua County: High incidence, buccal mucosa preponderance, and a close relation to betel quid chewing habit. Journal of the Formosan Medical Association, 106(3), 225-233.

Taioli, E., Zhitkovich, A., Kinney, P., Udasin, I., Toniolo, P., \& Costa, M. (1995). Increased DNA-protein crosslinks in lymphocytes of residents living in chromium-contaminated areas. Biological Trace Element Research, 50(3), 175-180.

Tisch, M., Enderle, G., Zöller, J., \& Maier, H. (1996). Cancer of the oral cavity in machine workers. Laryngorhinootologie, 75, 759-763.

Tisch, M., \& Maier, H. (1996). Squamous epithelial carcinoma of the tongue after occupational exposure to chromium VI compounds. Laryngorhinootologie, 75, 455-458.

Tsai, K. Y., Su, C. C., Lin, Y. Y., Chung, J. A., \& Lian, I. B. (2009). Quantification of betel quid chewing and cigarette smoking in oral cancer patients. Community Dentistry and Oral Epidemiology, 37(6), 555-561.

Türkdoğan, M. K., Kilicel, F., Kara, K., Tuncer, I., \& Uygan, I. (2002). Heavy metals in soil, vegetables and fruits in the endemic upper gastrointestinal cancer region of Turkey. Environmental Toxicology and Pharmacology, 13(3), 175-179.

Yassi, A., \& Nieboer, E. (1988). Carcinogenicity of chromium compounds. Chromium in Natural and Human Environments. New York: Wiley.

Younas, M., Shahzad, F., Afzal, S., Khan, M. I., \& Ali, K. (1998). Assessment of $\mathrm{Cd}, \mathrm{Ni}, \mathrm{Cu}$, and $\mathrm{Pb}$ pollution in Lahore, Pakistan. Environment International, 24(7), 761-766. 